\title{
HOW TO PUT PRESCRIPTION DRUG ADS ON YOUR SYLLABUS
}

\author{
Vanessa Carbonell \\ University of Cincinnati
}

This is the accepted version as submitted. Please cite the published version of record: "How to Put Prescription Drug Ads on Your Syllabus", Teaching Philosophy 37(3), 295319. https://doi.org/10.5840/teachphil201461917

American college students from the "millennial" generation grew up in a world saturated with ads for prescription drugs. Drug ads are such a ubiquitous part of our culture that students may not realize that it hasn't always been this way, or that the United States is one of only two developed nations in the world to permit these ads. While the average person spends about fifteen minutes per year with a doctor, she spends sixteen hours per year watching direct-to-consumer (DTC) prescription drug ads (Mintzes 2012). The practice of promoting prescription drugs directly to patients raises many important ethical questions. However, prominent undergraduate bioethics textbooks and anthologies rarely include any discussion of this important topic. ${ }^{1}$

The purpose of this essay is to make the case that the ethical issues raised by the current U.S. practice of DTC prescription drug advertising are worthy of study in philosophy courses, and to provide instructors with some ideas for how they might approach teaching the topic, despite the current relative scarcity of philosophical literature published on it. This topic presents a unique opportunity to cover ground in ethics, critical thinking, and scientific literacy simultaneously. As a case study, the practice of DTC advertising is both theoretically rich and universally relevant to students' lives. The nature of these ads-numerous, diverse, visually and thematically entertaining-makes them delicious fodder for in-class activities, small group work, discussion-based learning, creative projects, and customizable essay topics. I will offer a set of suggestions for approaching the study of DTC drug ads that is informed by my own experience doing so in bioethics courses. While this topic is obviously well suited for inclusion in a bioethics or contemporary moral issues course, it could also have great pedagogical utility as a scaled-down case study in courses in business ethics, ethical theory, critical thinking, or even Marxism. Ultimately, including this topic on your syllabus not only contributes to students' philosophical skills and knowledge, but also helps them become better informed as citizens and potential "consumers" of health care.

\footnotetext{
1 An informal survey of eight recent anthologies, including bestselling tomes from top publishers, reveals only one that includes a chapter or article on this topic-Parks and Wike, eds, Bioethics in a Changing World (2009). However, the included article (Kaphingst and DeJong, 2004) focuses on what consumers learn from these ads, not on the ethical permissibility of the ads in general. Correspondingly, not much in the way of normative analysis of this question has been published in mainstream philosophy or bioethics journals. However, some useful resources include La Barbera (2012), Mulligan (2011), and Wellington (2010). See also the forthcoming article, "The Ethics of Advertising for Healthcare Services" (Schenker, Arnold, and London, 2014), which considers advertising for doctors, hospitals, and clinics, a practice that raises some of the same theoretical and practical issues as drug advertising.
} 
Not insignificantly, drug ads are also a good way to introduce humor and levity into the classroom.

This essay has four parts. $\$ 1$ presents an overview of the role of DTC drug ads in the United States. ${ }^{2} \$ 2$ rehearses a principlist analysis of whether the practice of DTC advertising is morally problematic, all things considered. The purpose of this section is not to argue for a particular moral conclusion, but to identify the key questions, suggest relevant background readings, and digest some of the pertinent empirical information, with the hope of reducing the burden of preparation instructors would face in adding this topic to their syllabus. $\$ 3$ presents a set of suggested exercises and assignments: an interactive whole-class examination of television ads, a small-group analysis of magazine ads, a set of possible topics for an argumentative essay assignment, and a creative individual or group video project. Finally, $\mathbb{4} 4$ makes some concluding remarks about the benefits and the potential pitfalls of incorporating DTC drug ads into philosophy courses.

\section{Drug Ads in Context}

Drug companies spend tens of billions of dollars annually promoting their products via free samples, sales pitches to prescribers, and direct-to-consumer advertisements (Donohue et al 2007). Direct-to-consumer prescription drug ads are disseminated via TV and radio, print, and the internet. In the United States, the Food and Drug Administration (FDA) divides these ads into three types. "Product claim ads" link a particular drug by name to a particular condition, claiming the drug treats the condition. "Reminder ads" refer to the drug name but not the condition. "Help-seeking ads" (or "disease awareness" ads) discuss a condition but not a drug (FDA 2010). The United States and New Zealand are the only developed countries in the world where "product claim ads" are legally permitted. Australia and Canada permit the more minimal "reminder" and "help-seeking" ads (Wellington 2010). These more minimal ads are also familiar to viewers in the United States; ads that appear to be neutral public-service announcements raising awareness of a disease typically direct viewers to a website that turns out to be a marketing site for a branded drug.

While DTC advertising of prescription drugs has long been legally permitted in the United States, it did not become widespread until the 1990's. Regulations passed by the FDA in 1969 required drug ads to communicate every risk of the drug being promoted, making such ads cumbersome (Mulligan 2011). Nevertheless, after pharmaceutical giant Schering-Plough's new antihistamine Claritin was approved by the FDA in 1993, a relentless and legendary direct-to-consumer marketing campaign was unleashed on the American public (Hall 2001). In 1997, the FDA issued a draft of new, relaxed regulations on television advertising, requiring only that TV and radio ads list the major risks of the drug, as long as viewers and listeners are directed to other sources (such as a magazine ad or their doctor) where they might learn about all the risks (Mulligan

\footnotetext{
${ }^{2}$ My discussion focuses on the United States, where DTC drug ads are rampant and where health care is treated as a consumer good. The topic is surely philosophically and pedagogically interesting enough to be a worthwhile case study for philosophy teachers in other parts of the world; however, the ads themselves will obviously not carry the same cultural significance to students who are not bombarded with them on a daily basis. The normative question of whether the ads should be permitted is timely in many parts of the world, particularly in Europe where there has recently been a push to legalize DTC advertising.
} 
2011). Thus began the current era of DTC marketing, during which big-name drugs like Viagra, and the ads promoting them, became inescapable features of American culture.

Prescription drugs, and the ads promoting them, are a growing business. In the ten-year period starting in 1996, total real spending on DTC drug ads more than tripled; DTC spending as a percentage of overall sales also increased more than twofold (Donohue et al 2007). The passage of Medicare Part D in 2006 enabled millions more Americans to afford prescription drugs, expanding the audience for DTC ads considerably. Meanwhile, regulatory oversight and enforcement significantly decreased. The FDA claims in its consumer educational materials that it "ensures that all prescription drug promotion provided by drug firms is truthful, balanced, and accurately communicated" (FDA 2010, p. 1). Yet the FDA currently does not require companies to submit ads for review before they are presented to the public. Companies that place misleading ads are subject to penalties after the fact, but the number of warning letters sent by the FDA has decreased dramatically even as the number of ads has increased (Liang \& Mackey 2011). In recent years the FDA has employed only a handful of staff to review the tens of thousands of ads submitted each year (Mulligan 2011).

Although the FDA appears unable to enforce compliance with its existing regulations, it has nevertheless recently proposed to make the regulations somewhat more demanding. Recall that TV and radio ads are now required only to list the major risks of the drug - called the "major statement"-as long as they make "adequate provision" for consumers to find the complete list of risks elsewhere, such as in a corresponding magazine ad (FDA 2012). (Confusingly, the complete list of risks is known as the "brief summary". In magazine ads, the "brief summary" is the not-toobrief page of dense print hidden on the reverse side of the colorful ad page.) In 2010, the FDA proposed new guidelines for the "clear, conspicuous, and neutral" presentation of the risks and contraindications of an advertised drug - that is, the information conveyed in the "major statement" (DHHS 2010). In order to count as "clear, conspicuous, and neutral," the information must meet specific standards governing understandability (e.g., no jargon); readability (e.g., clear contrast with background colors); volume, articulation, and pacing; and the absence of distracting or competing audio or visual elements. FDA's own review of thirty TV ads from 2008 found that one third of them violated the "clear, conspicuous, and neutral" guideline (DHHS 2010, 15379-81). The new standards have spurred some noticeable changes; ads now rarely feature a strange voice rattling off a list of side effects with the speed of an auctioneer.

It is useful for students to have some grasp of the nuts and bolts of how DTC advertising works - the different types of ads, the main regulatory guidelines-before attempting an ethical analysis of the practice. The nuts and bolts can be mastered quickly by using particular ads as examples, either as a class or in small groups (more on this in \$3). The FDA maintains a useful website explaining the guidelines and giving examples of ad violations (FDA 2012). But perhaps equally important, students need to be aware of the background conditions that determine which drugs are being advertised in the first place. While some of this background is no doubt old news to instructors, students who have lived their whole lives in a DTC ad-saturated culture may never have stopped to think about why they hear ads for seasonal allergy medicines and not for, say, penicillin. (Relatedly, instructors should not assume that all students have a clear grasp of the distinction between brand-name and generic drugs, or the distinction between overthe-counter and prescription-only drugs.) 
Most large ad campaigns are for new drugs and are launched within a year of the drug's FDA approval (Donohue et al 2007). Time is of the essence, because patents on new drugs expire after twenty years. New drug compounds are typically patented early in the development process, before the clinical trials and FDA approval process have begun. By the time the drugs make it to market, the window for companies to exclusively sell the drug before the patent expires is far less than twenty years. During this window, the manufacturer has a monopoly and makes an enormous profit in a short amount of time, without having to compete against cheaper generic versions of the drug. While drug companies use a variety of legal tactics to extend patents incrementally beyond twenty years, an even more profitable strategy is to submit a close chemical relative of the drug for approval as a "new" drug, thus starting the patent cycle over from scratch. These are known as "me-too" drugs; sometimes they turn out to have usefully different risks or interactions from the original, but often they are so closely related to the original drugs as to be almost indistinguishable (Brody 2007, Angell 2005). As the patent was expiring for the heartburn drug Prilosec (omeprazole), the manufacturer applied for FDA approval for a sister drug, Nexium (esomeprazole), which contains a different isomer of the same compound (Angell 2005). The manufacturer marketed Nexium heavily to Prilosec users and clinicians, encouraging them to switch to the expensive new drug just as Prilosec's patent was expiring, despite the impending availability of the cheaper, generically manufactured omeprazole.

New drugs need not be shown to be more effective than existing drugs in order to be approved by the FDA; they only need to be relatively safe and marginally better than a placebo. ${ }^{3}$ However, if companies can prove that a drug is "more effective" in some way than its competitors, then they are allowed to exploit this fact in marketing. The company that made Nexium ran trials showing that a high dose of Nexium was more effective than a low dose of its own former blockbuster Prilosec for a particular condition, esophageal erosions. Despite not having tested to see whether a comparable dose of Prilosec would be just as good, this research allowed the company to heavily market Nexium as an improvement over Prilosec (Angell 2005). Some physicians no doubt were quite scrupulous in evaluating whether their patients were likely to derive any new benefit from the "purple pill" they saw on TV. But physicians are extremely busy, so it is understandable they might acquiesce to what seem like harmless patient requests, or defer to the information provided by drug companies-marketing disguised as officially sanctioned continuing education (Brody 2007). (Drug companies spend even more money on marketing to physicians than on DTC advertising. This practice is also fertile ground for ethical analysis.)

To recap, before delving into the philosophical arguments about DTC drug advertising, it's worth knowing that (1) the most advertised drugs are new drugs; (2) new drugs are not necessarily more effective than, or even relevantly different from, older, cheaper drugs; (3) given the patent system, manufacturers have huge financial incentives to maximize sales during the window in which they have a monopoly, and to extend that window as long as possible. Finally, since new drugs are mainly tested in small, short clinical trials, we know less about their long-term effects, contraindications, and adverse events than we do for older, generic drugs. This was famously illustrated in the case of

\footnotetext{
${ }^{3}$ This is sometimes snarkily referred to as being "better than nothing," but this is misleading, since on the one hand placebos are not nothing, and on the other hand a drug can be approved despite actually being worse than a placebo in the sense that it is more dangerous and only marginally more effective.
} 
Vioxx, a heavily-marketed new arthritis drug that was withdrawn from the market after it was found to cause heart attacks. Victims of the Vioxx scandal would be justifiably outraged not only that a drug caused them so much harm, but that they might not have taken the drug at all had it not been advertised on television. The fact that safety is an issue for new drugs in particular, and new drugs are the most heavily marketed, has become a central part of the debate over the ethical permissibility of DTC advertising (Mintzes 2012).

\section{Ethical Analysis of DTC Advertising Practices}

\subsection{Defining the question}

How should instructors guide their class through an analysis of the ethical implications of DTC prescription drug advertising? First, it's useful to have a particular question in mind, around which lecture or discussion can be organized. This may seem obvious, but as instructors we don't always do a very good job of it; when students aren't all on the same page about what question is being asked, an aimless and unproductive discussion is likely to result. Drug advertising is a complex public policy issue-the moral question can be difficult to disentangle from related legal, political, and empirical questions. Being specific about the question will not magically transform a complicated problem into a simple one, but it is at least a place to start. In a bioethics course, the question around which my own discussion is organized is, "Is the current American practice of DTC drug advertising morally problematic, all things considered?"

This question is not perfect. Obviously, what counts as "morally problematic" will vary with your moral theory or with what factors you take to be morally relevant, and the answer will likely be a matter of degree, not an absolute yes or no. But this question serves to narrow down our task along several dimensions: we are focusing on the advertising itself (and not, say, the entire health care system); what we are evaluating is the moral status of the practice (and not, say, the blameworthiness of individuals who participate in the practice); we are prioritizing the moral and not the legal question (though answering the moral question might help us tackle the legal question afterward); and, insofar as possible, we want to make an all things considered judgment that considers both positive and negative aspects of the practice and takes into account the contexthow the practice actually works in our society, given various background facts. This idea of paying careful attention to the context may be thought of as taking a "non-ideal theory" approach. From this non-ideal perspective, we ask not whether DTC drug advertising would be problematic in a society with an ideal political structure and ideal health care delivery system, but whether it is problematic in our society, in light of facts about the way the practice actually works, including some level of noncompliance with regulation. Idealized questions are also worthwhile, but given a finite amount of course time, it makes sense to start with the pressing normative predicament our students face as citizens - that is, here is how things are, what should we think of it? And if we find that the practice is morally problematic, what should be done about it?

\subsection{Principles-based analysis}

How should we try to answer the all-things-considered moral question? In a bioethics course, a good place to start is with the prominent theoretical framework 
known as "principlism". The classic philosophical defense of this approach was given in Beauchamp and Childress's Principles of Biomedical Ethics in 1977, now in its seventh edition (2013) ${ }^{4}$. Many bioethics instructors will have already incorporated this framework throughout their courses, so their students may already be quite adept at working within the framework by the time they get to this topic. Even in a course in contemporary moral and social problems, the principles are an efficient way to organize inquiry, and can be conveyed in a short lesson. Of course, instructors may instead be working within a framework in which practical moral problems are evaluated according to various normative ethical theories, such as consequentialism, Kantianism, virtue theory, and the ethics of care. Many of the same considerations that arise using a principlist approach will also arise using the more theoretical approach. (After all, principlism is essentially a distillation of the central principles that feature in the traditional moral theories. ${ }^{5}$ )

The four moral principles central to the principlist framework in bioethics are autonomy, nonmaleficence, beneficence, and justice (Beauchamp and Childress, 2013, hereafter BC). Since anyone teaching a bioethics course will already be familiar with this framework, my goal in what follows is not to discuss the theoretical foundations of the principles in any depth, but simply to survey some of the considerations that are likely to be relevant to a principlist analysis of the ethics of DTC advertising and to suggest some useful background readings for both instructors and students.

Autonomy. The general idea behind the principle of autonomy or "self-rule" is that persons should be free to guide their own actions and determine the course of their own lives, perhaps most especially with respect to issues regarding their own bodies, to the extent that they are able. The principle of autonomy is the philosophical justification that lies behind such practices as allowing competent adults to make their own medical decisions (including the decision to refuse treatment), requiring the patient's informed consent for procedures and participation in research, and telling patients the truth about their diagnosis and prognosis. Beauchamp and Childress claim that two conditions are necessary for a person to exercise autonomous choice in the healthcare context: "liberty (independence from controlling influences) and agency (capacity for intentional action)" (BC 2013, 102).

Does the practice threaten liberty? The purpose of advertising is to get you to purchase things you otherwise wouldn't. And we know from empirical studies that advertising achieves its goal-it results in more requests for prescriptions (which are usually honored) and more diagnoses (Mintzes 2012). So it seems obvious that this practice exerts a controlling influence on human behavior. However, prescription drugs are different from other consumer products: you cannot simply purchase them; at most you can request them from an expert intermediary who is professionally responsible for advising you on what is best for your health. A question for students might then be: Does the fact that the prescriber acts as an intermediary mitigate or exacerbate the degree to which DTC advertising is controlling (i.e., liberty-reducing)? If the prescriber's judgment was necessary for the outcome, is the advertising less to blame? Or is the prescriber's

\footnotetext{
${ }^{4}$ One need not think that principlism is the best philosophical method for answering moral questions in order to think that it is a good pedagogical approach for addressing such questions in the classroom.

5 Alternatively, Wellington (2010) takes a human rights approach to tackling the question of DTC advertising, asking whether pharmaceutical companies are violating the human right to health. The principles of autonomy and nonmaleficence feature in her analysis, even though it is not a standard "principlist" analysis.
} 
action also a form of control over the patient? Most prescribers are subject to an onslaught of marketing and "education" from pharmaceutical companies that dwarfs the direct-to-consumer side of things (Angell 2005, Brody 2007, Goldacre 2012). While our task here is only to evaluate consumer advertising, it is natural to wonder whether the "controlling influence" of such advertising is simply the first step in a liberty-reducing process; once the advertising gets you in the doctor's office, even if you do not request a drug by name, you could be subject to the controlling influence of the same marketing machine, via its influence on your physician. On this question, it might be useful to have students read Brody (2007) Chapter 9, "The Drug Rep Today," to get a sense for the way drugs are marketed to prescribers.

Clever students might propose that going to your doctor, discussing your symptoms, being diagnosed with a disease, and receiving treatment for that disease, are good things. Thus, if it is the "controlling influence" of the TV ads that brought this process about, then being controlled is not necessarily a bad thing. This raises two important issues. First, whether or not DTC advertising has helpful or harmful effects is in itself a separate question, which will be addressed via an analysis of the principles of nonmaleficence and beneficence. An increase in treatment for disease may or may not be a good thing, depending on whether the treatment is really necessary and has a favorable benefit-to-harm ratio. Second, the comment reveals that we had been presupposing that liberty is a good thing and control (considered independently of its effects) is a bad thing. Students should feel free to question this presupposition-is freedom from control, by itself, valuable? One way to approach this question is to ask whether DTC advertising is manipulative and coercive, or merely persuasive (BC 2013, 138-139). Manipulation and coercion are, presumably, morally problematic by default, whereas persuasion may be considered a benign type of influence. Thus if students can determine whether these ads are manipulative or merely persuasive, they will have gone some length toward figuring out whether these ads exert a problematic form of control.

So much for liberty; does the practice also threaten agency? Autonomous agency requires that the actions, decisions, or choices in question be, at the very least, intentional and informed (done with understanding) (BC 2013, 104). Does a person who takes action (say, making a medical appointment or requesting a medication) on the basis of DTC advertising do so intentionally - that is, not accidentally, and on the basis of her own plan? Here the issue may be framed as whether advertising causes us to act in unplanned ways, or gives us plans we don't endorse. One provocative way to pose this question to students is to ask whether drug ads ever have a "brainwashing" effect on viewers. Less provocatively, does constant exposure to drug advertising plant in us desires or insecurities or fears-say, the desire for clear skin, or the fear that we have a serious illness - that operate subconsciously, undermining the sincerity of our plans?

Actions or choices that exhibit autonomous agency must also be informed-done with understanding. But just how much information does a patient require, and how sound must her reasoning be, for her request for a prescription drug to count as sufficiently informed? The clinician serves as a gatekeeper, hopefully protecting patients from their own misinformation. But we value autonomous choice even independently from its results. So if a patient's request is based on a gross misunderstanding, it is less than fully autonomous, even if (say by accident) it turns out that the drug would benefit her and the physician judges that she needs it. Thus we should ask whether advertisers are, at a minimum, fulfilling a negative duty not to misinform. Do ads (1) contain false or misleading information; (2) leave out important or relevant information; or (3) encourage 
faulty reasoning? In an exercise explained in $\$ 3$, I suggest how students might use real ads to examine these questions.

In addition to asking whether particular ads undermine the "informed" requirement of autonomous agency by misinforming patients, students should think about the effect of the total volume of drug advertising, which introduces a huge amount of "information" into our culture-information about medical conditions, symptoms, and treatments. Defenders of DTC advertising insist that this information enhances autonomy by making consumers aware of treatments for bothersome health problems, or even by making them aware of health problems they didn't know they had. This allows patients to play a more active role in their own health care, a central aim of the increased focus on patient autonomy in recent decades. But does simply being exposed to more information mean that patients are better informed? Does exposure to information always promote autonomy? Is there ever a sense in which knowledge of one's health options makes one less free? Students' views about these questions may evolve as they examine some of the empirical research into the effects of DTC advertising, which I discuss in the next section. ${ }^{6}$

Nonmaleficence and beneficence. The principle of nonmaleficence holds, quite simply, that we should not harm others. The principle of beneficence holds that we ought to promote the welfare of others. In the case of DTC advertising, we are not asking whether particular people are harming or helping others, but rather in what ways the practice is harming or helping those affected by it. Of course, at some level, there are particular persons who are-causally, legally, morally_responsible for the existence and content of the ads and for the regulatory approval of the drugs themselves. And there are individual prescribers who, in their capacity as gatekeepers for prescription drugs, may be failing or succeeding in upholding their individual duties of beneficence and nonmaleficence. However, we can assess the overall effects of the practice itself without isolating the roles played by individual agents, and without determining the blameworthiness of those agents.

As with most practices in healthcare and elsewhere, we can expect that DTC advertising will have some harmful effects and some beneficial effects. Since this is an

\footnotetext{
6 Questions about autonomy are naturally paired with questions about paternalism-that is, limiting people's autonomy for their own good. Even if students conclude that exposure to drug advertising does not enhance but in fact undermines autonomy overall, they still might wonder whether regulating or banning these ads counts as a paternalistic interference with viewers' autonomy. To force viewers to listen to a drug's side effects, or to prevent viewers from viewing certain kinds of ads at all, is a restriction on one kind of freedom (freedom to hear directly from the manufacturer about the drug) even if it has the result of protecting another kind of freedom (freedom to make informed healthcare decisions without controlling influences). But it is not clear that the "freedom" to hear directly from a manufacturer about a drug really counts as a case of the kind of "freedom of action" we are normally concerned with when laws or regulations are criticized as paternalistic (Dworkin 1973). More plausibly, regulations on drug ads do not restrict the freedom of consumers, but rather restrict the freedom of the manufacturers. Thus at most such regulations might be a case of "impure paternalism" in which one party (the manufacturers) has their freedom restricted to protect another party (consumers) from harms that are at least somewhat selfinflicted (Dworkin 1973). Still, regulating the ads would only be paternalistic if the consumers played a significant role in bringing the harms of overtreatment upon themselves. Since overtreatment has many causes, and since prescribers themselves see the ads and may be influenced by them, regulating ads could be justified non-paternalistically as a type of prohibition on harm-to-others.
} 
empirical matter about which it is difficult to make educated guesses, at least some engagement with the empirical literature is necessary; this can take a variety of forms, including having students read assigned articles as background, having students research particular empirical questions on their own, or simply presenting an overview of pertinent findings via a handout or lecture. Accessible articles to assign include Kaphingst \& Dejong (2004) on the question of whether drug ads succeed in "educating" consumers, and Brody \& Light (2011) on the several mechanisms by which drug marketing has a detrimental effect on public health.

To keep students actively engaged, I like to have them brainstorm about the possible harmful and beneficial effects before we look to see which effects have been studied and what the results of those studies are. One would guess that DTC drug advertising would cause an increase in: doctor visits, requests for drugs, prescribing of drugs, diagnosis and treatment of disease, drug prices, and healthcare costs overall. Less directly, one might expect an increase in side effects, overdoses, adverse events, hypochondria, and the medicalization of normal human experience. Overall medical knowledge could increase or decrease, as could the stigma of certain diseases and the use of counterfeit, illegal, or over-the-counter drugs. The doctor-patient relationship could get better or worse.

The brainstormed list of effects will, all by itself, raise interesting conceptual and philosophical questions. For example, trying to figure out how to individuate items on the list requires us to disentangle some causal relationships; an increase in the diagnosis and treatment of disease is not the same as an increase in wellbeing, because the diagnosis and treatment of disease does not, of course, always result in an improvement in people's wellbeing. (And what does wellbeing consist in, anyway? This is another worthwhile topic of inquiry.) Relatedly, how do we know when increased diagnosis and treatment are in fact instances of "overdiagnosis" and "overtreatment"? Time spent disentangling these issues is not wasted time, especially in a bioethics course. Brody \& Light (2011) is a helpful source on these questions, as are several recent documentary films, including Escape Fire (2012) and Money and Medicine (2012).

What does social science research tell us about the direct effects of DTC advertising itself? There has been quite a lot published on this question in the past two decades, from a variety of fields, including marketing, business, economics, and public health. Different studies are aimed at answering different questions; background assumptions and research methodologies vary considerably. ${ }^{7}$ Looking at any one study can leave a very incomplete picture; this can be a good opportunity to work with students on basic information literacy. The most careful, comprehensive, and up-to-date source on this question is probably Mintzes (2012), which reviews a large body of

\footnotetext{
7 In one study from economics, a complex mathematical model is used to assess the impact of DTC advertising on welfare. Consumers are assumed to be utility maximizing agents, physicians are assumed to make the decisions that consumers would make if they had full information, and the prescription of a statin drug to someone with high cholesterol is assumed to increase her welfare. Perhaps not surprisingly, this study finds that DTC advertising for statins has increased welfare (Jayawardhana 2013). Yet as Mintzes (2012) shows, econometric studies on statin use tend to be methodologically questionable, and even studies that use actual evidence of lowered cholesterol levels as an outcome may fail to prove what they claim to prove. And as Brody and Light (2011) argue, there is reason to be suspicious of whether the explosion of statin use is really a good thing-DTC advertising tends to have its largest impact on patients who have the least severe disease and are least likely to benefit. Indeed the advertising itself seems to be affecting professional guidelines for where to put diagnostic thresholds for various disease states.
} 
research, focusing only on those studies that meet a high bar of methodological integrity. ${ }^{8}$ It may be a good idea to make this paper available to students (especially for citing in essay assignments), though it is not philosophically interesting enough to serve as required reading.

Mintzes' review found evidence of the following effects of DTC advertising: increased patient demand for the advertised drugs, increased doctor visits, increased volume of prescribing, and shifts in prescribing to the advertised drugs. However, there was no evidence that any of these effects constituted a net benefit to public health. Indeed, the studies show that DTC advertising is linked to increases in prescriptions that would not have been the physician's first choice, shifts to less cost-effective drugs, increases in prescriptions for unapproved uses (e.g., antidepressants for "adjustment disorder"), increases in "inappropriate" prescribing (e.g., Vioxx in patients for whom it was not the best choice), and increases in prescribing of new drugs that later turned out to be extremely dangerous (notably, Vioxx). To the extent that DTC advertising causes people to purchase drugs that they really do not need, it's worth noting that some of the costs of those unnecessary drugs will ultimately be paid by the taxpayers via Medicare and Medicaid, and by policyholders via increases in premiums for private insurance (Mulligan 2011).

As for other possible benefits, Mintzes finds no evidence that DTC advertising reduces the stigma associated with disease or that it plays an educational role. Quite the contrary: studies show that drug advertising causes consumers to have false beliefs about the prevalence of conditions and the effectiveness and risks of drugs (Mulligan 2011, 458 and 462). Here it is worth connecting the discussion of harms to the prior discussion of autonomy. Simply exposing people to more information does not guarantee that they will experience an increase in understanding. When patients are "epistemically vulnerable," information that is not properly tailored to their needs and capabilities may in fact inhibit their agency rather than bolster it (Womack 2013).

Justice. Evaluating the practice of DTC advertising from the perspective of justice is no simple matter. It is difficult to disentangle the practice from its context: a society with deeply entrenched social inequalities and a health care system that is shaped as much by profit motives as by public health needs. For example, DTC advertising might result in people paying more for a drug than they can really afford or than they otherwise would. If this is an injustice, it has many causes: the fact that drug prices are unregulated, the fact that many citizens lack insurance coverage, and the fact that DTC advertising shifts consumer demand. Thus DTC advertising might simply recapitulate or exacerbate preexisting injustices in the system. But in keeping with the approach I have advocated-that is, non-ideal theory-we can simply evaluate the practice as we find it, that is, embedded in its actual context, warts and all.

There is no theoretical consensus as to what the principle of justice consists in. We can make the principle theoretically neutral- "resources should be distributed fairly" - only at the cost of rendering it fatally vague. In my course, we evaluate the

\footnotetext{
${ }^{8}$ Mintzes reviewed studies from 2004 to 2011 using the same criteria as an earlier review by Gilbody et al (2005), which covered 1987 to 2004. All told, between 1987 and 2011, thirteen studies on the benefits and harms of DTC advertising met the high bar for inclusion, namely that they used "methods able to assess these outcomes: randomized controlled trials (RCTs), controlled before-and-after studies, interrupted time-series analysis, and cross-sectional studies with a concurrent control group" (Mintzes 2012, 264).
} 
practice from three perspectives - utilitarian, egalitarian, and libertarian - in addition to asking whether it serves or undermines the interests of socially marginalized or vulnerable groups. ${ }^{9}$ We are able to go into this level of depth because the topic of drug advertising is grouped with other questions about resource allocation (e.g., organ donation), allowing the theoretical work to do double-duty.

The utilitarian and libertarian perspectives are fairly straightforward and draw on empirical and philosophical issues that arose in examining autonomy, nonmaleficence, and beneficence-I won't rehash them here. However, it is important to note that, when considering the practice from the perspective of justice, we must consider how it fares compared to relevant alternatives. Such alternatives may include a complete ban on DTC advertising, an "anything goes" unregulated market, and forms of regulation that are more stringent than the current system. There is room for students to think creatively here about what kind of regulations on advertising, if any, might be successful in protecting the public health.

Since egalitarianism is trickier to convey than utilitarianism and libertarianism, it may be helpful to have students read Nielson (1989) and Daniels (1981) to introduce them to examples of egalitarian thinking in the healthcare context specifically. These authors argue that equal access to adequate health care is necessary for preserving autonomy and equality of opportunity, respectively, and they introduce notions like "basic needs" and single-tier vs multi-tier healthcare systems. Students can then examine whether DTC advertising as it is currently practiced aligns with egalitarian goals.

Finally, one important justice-related consideration that crosscuts the utilitarian, egalitarian, and libertarian theories is the question of whether a given practice or policy distributes benefits and burdens unfairly by gender, race, ethnicity, or any group characteristic associated with social marginalization or vulnerability. We know that there are measurable disparities in the accessibility of health care, and in health care outcomes, between socially marked groups in the United States (BC 2013, 264-266). The question we are interested in here is whether DTC advertising introduces, recapitulates, or exacerbates any such disparities. One reason this is worth taking seriously is that health care seems to be specially related to human flourishing in a way that many other consumer opportunities that cross our TV screens are not.

How DTC advertising affects socially marginalized or vulnerable groups is largely an empirical question. What do we know? Women are more likely than men to be targeted by the ads and to request the advertised drugs, but also more likely to be harmed by drugs that turn out to be dangerous (Mintzes 2012). One survey with a large sample also showed that African Americans and Hispanics had less exposure to DTC advertising than whites, but were more influenced by the ads they did see. African Americans who had viewed DTC advertising were more likely than whites to request the advertised drugs, but less likely to have the request honored (Lee and Begley 2010). We also know that ads frequently present information in a way that is too technical for consumers to adequately comprehend (Kaphingst \& DeJong 2004). Assuming that ads are more likely to mislead consumers with lower levels of literacy or educational attainment, we can ask: should "less literate" or "less well-educated" count as markers of

\footnotetext{
${ }^{9}$ See Chapter 7 of Beauchamp and Childress (2013) for discussion of these and other theories of justice. Another place to look for nontechnical discussion of different approaches to justice is Michael Sandel's Justice (2009).
} 
a "vulnerable group" with respect to distributive justice in health care? (For more on the controversy over who counts as vulnerable in bioethics, see BC 2013, p. 267.)

It is also worth considering what messages the ads express, for example with respect to stereotypes about gender and about diseases. Studies show that ads for antidepressants, for example, overwhelmingly use female models or actresses and often portray them in gender-stereotyped roles (Mintzes 2012, 269). The most obvious harmful consequence of this disparity is that women, in responding to the ads, could be disproportionately overdiagnosed or misdiagnosed with depression and overtreated or mistreated with potentially harmful drugs. (Indeed, recent research suggests that depression is widely overdiagnosed and overtreated. One in four women in their 40's and 50's takes an antidepressant [Rabin 2013].) But a less obvious harm is that anyone who sees the ads-including women and men who are not at all depressed-could come to harbor stereotyped views about women or about depression. Thus the practice of DTC advertising-like all advertising, perhaps-can contribute to group-based disparities even independently of direct effects on health-related behavior or outcomes. Students may also be interested in examining ads for erectile dysfunction drugs, testosterone supplements, and birth control pills to look for evidence of stereotypes pertaining to gender or sexuality.

After applying the principlist framework, the class will need to step back and assess the results. Perhaps the most problematic feature of this framework is the need to reconcile divergent verdicts within and between the principles. In my experience, students will not come to a unanimous judgment. Some will find that the practice fares poorly according to all of the principles. Others, especially those drawn to a libertarian conception of justice, will see more conflict. Instructors might ask students from differing camps to defend the relative weights they give to the different moral principles. Such arguments can also be worked out in more detail in follow-up essays, as I discuss below.

\section{Class Exercises and Assignments}

Both common sense and empirical research show us that engagement and learning are promoted when we give students something active to do in class, when we have them to work collaboratively in groups, when we make use of realistic case studies, and when they feel a sense of creative investment and ownership in the assignments they are asked to produce outside of class (Prince 2004, Umbach and Wawrzynski 2005, Nilson 2010, Weimer 2013). In this section I suggest two in-class activities and two out-of-class assignments that are aimed at capitalizing on the creative potential of DTC advertising as an object of study. These activities and assignments could of course be modified in a variety of ways to meet distinctive needs of any particular course. In my own course, I have included some of these activities and assignments in addition to spending a significant chunk of course time (two to three hours across two to three class meetings) leading the class through an in-depth philosophical analysis of the central normative question, as outlined in the previous section. These activities and assignments can serve as complements to that analysis: as a warm-up "appetizer" to the topic; as a chance to get familiar with real-life examples; as intermittent hands-on investigations of particular normative questions; and as a culminating project done alone or in groups after the inclass coverage of this topic has concluded. 


\subsection{Whole-Class Television Ad Analysis (10-20 minutes)}

This activity works well at the very beginning of a unit on DTC advertising, and can be done in a class of any size, provided networked audio-visual resources are available. Numerous current and historical prescription drug ads can be located on the web, most obviously on YouTube. Choose a set of "product claim" ads representing a variety of conditions; some ads are more interesting than others, so a little bit of advanced planning pays off here. I've shown ads for Zoloft (for depression), Latisse (for inadequate eyelashes), Botox (for wrinkles), Crestor (for high cholesterol), Lunesta (for sleeplessness), and Viagra (for erectile dysfunction) among others. Before showing the ads, ask the students to write down a set of basic questions (or provide them with a handout): What condition is the drug for? What are the symptoms of this condition? What benefits does the drug provide? What side effects or risks come with the drug? What overall message does the imagery or story of the ad convey about the condition or the drug? And finally: what questions are you left with about the condition or the effectiveness of the drug after having seen the ad? For each ad, give the students a few moments after watching it to write down the answers to the questions, and then solicit answers as part of a moderated whole-group discussion. This activity is a convenient time to introduce or reiterate the basic FDA distinctions and requirements-for example, you may pause an ad to point out the features that are included in order to comply with requirements, such as "see our ad in Parenting magazine," which directs the viewer to an alternate source of the "Brief Summary" information. You can also return to these videos in the middle of the normative analysis, in order to examine questions about autonomy, harm-vs-benefit, group-based stereotypes, etc., in the context of a particular ad.

\subsection{Small-Group Print Ad Analysis (25-45 minutes)}

This activity works well in smaller classes, but there is no reason it cannot be scaled up or modified to work in a lecture hall. Bring to class a stack of mass-market magazines of the sort that contain DTC advertising. Many such magazines contain up to a dozen different drug ads in a single issue. (I usually put out a request for magazine donations within my department. I bring one per student; fewer would also suffice. To get a wide sample of ads for different demographics, vary the types of magazine.) Give each student a magazine and have the class form small groups (3-4 students). Ask them to locate and tear out all the prescription drug ads in their magazines. The instructor can of course remove the ads beforehand. However, part of the purpose of this exercise is to get students to be more consciously aware of the volume of ads that they see regularly, if not in their own mailbox then in waiting rooms and on airplanes, etc. And simply giving them something physical to do is a good way to keep them awake and engaged at little cost of class time. Once each group has accumulated a stockpile of ads, have the group members collectively pick three or four that they find most intriguing. For each ad, the group then collaboratively fills out an ad analysis (similar to the television ad analysis above): Condition? Symptoms? Benefits? Harms and risks? Message conveyed? Questions raised? Time permitting, have a representative of each group show the ad to the whole class and report on what questions it raised. Do the ads meet the FDA's 
requirement of neutrality? Are benefits emphasized differently than risks? Is the information in the "Brief Summary" understandable to the average person?

Part of the purpose of this exercise is to draw students' attention not only to the quality of the information that is displayed in the ad, but also to the information that is not conveyed in the typical ad, so that they may consider how this missing information bears on questions about autonomy, harms and benefits, and questions of distributive justice. According to FDA guidelines, the following items are not required to be included in drug advertising: cost; whether a generic alternative exists; whether other, safer drugs exist; whether behavioral changes are effective for the condition; how prevalent the condition is; how the drug works; how quickly it works; and how many people who take it will benefit (FDA 2012). You will quickly notice that ads also make claims about research without giving supporting details, such as how many people participated in a particular trial or how long it lasted. Ads sometimes contain claims about improvements in relative risk or incidence of a certain condition or symptom without giving information about absolute risk or incidence. For example, an ad for a multiple sclerosis drug says that it reduced the frequency of disease relapses over one year by $52 \%$ compared to another drug. What does this mean? It could mean that patients went from having-on average-about 10 relapses per year on the alternate drug to about 5 , or it could mean they went from having 1 relapse per year to "half a relapse" (on average). And how many relapses do patients have on no drug, or on a placebo? And what about the serious side effects also listed-how prevalent are they? Looking at particular ads is a great way to get students thinking about the requirement that patients must be informed in order to exhibit autonomous agency, as well as the possibility that selling patients on a new drug could in fact harm them.

On the other hand, this activity also presents opportunities for students to find and discuss ads that they think have the potential to be quite beneficial to patients, including to people their own age. In one of my classes, a representative from one group selected an ad for a new drug for attention-deficit hyperactivity disorder (ADHD) and pointed out various ways in which the ad was misleading. As if on cue, another student chimed in that her little brother was taking that exact medicine and it had benefited him enormously. A profitable discussion ensued.

\subsection{Argumentative Paper: Three Options}

An argumentative paper assignment is an opportunity for students to think more deeply about their own views on this topic and to engage in a more careful analysis than is always possible in class. How the topics are framed will of course depend on particularities of each course, including what readings were assigned. Let me suggest three general topics. First is simply to ask students to defend an answer to the central normative question explored in class: is the current American practice of DTC advertising morally problematic, all things considered? Although this topic was essentially rehearsed in class, staking out and defending a precise answer to the question will require them to think about how to weigh the different elements of the principlist framework-no easy task. The second topic is narrower: select a real-life ad from television, print, or the internet, and write an analysis of whether that particular ad is morally problematic, using some or all of the principlist framework as a guide. This topic encourages a bit more creativity by giving students the chance to seek out an ad-or a drug - that they find particularly interesting. However, it also necessitates a bit of outside 
empirical research, as students will need to determine how well the ad represents the scientific reality. Depending on what drug is chosen, this topic is a great opportunity for students to explore not just DTC advertising, but related issues in bioethics, such as treatment vs enhancement, overdiagnosis and medicalization, quality vs quantity of life, mental health issues, etc. Finally, the third topic I will suggest is somewhat more openended. It asks students to develop a set of DTC advertising regulations to replace those currently used by the FDA, and to defend the proposed regulations by appealing to the empirical research and moral principles we studied. The regulations could be either more lenient or more restrictive than those currently in place, and could govern not only what sorts of things can be said in ads, but what sorts of drugs can be advertised at all. (For example, one proposal in the EU would have only allowed ads for drugs that treat AIDS, diabetes, and asthma [Hasman \& Holm, 2006].)

\subsection{Ad Makeover Project}

Some instructors relish opportunities to get students engaged in "outside the box" assignments that have them working together outside the classroom and/or producing something other than the traditional term paper. Here is one such project: ask students to take an existing television ad and give it a makeover by producing an alternative video ad for the same drug based on research into the condition and the drug's effectiveness. The idea is to make an ad that is more informative, more balanced, and more aligned with ethical principles regarding the delivery of health care. Of course the new "ad" may not be as effective in convincing anyone to buy the drug, but then that becomes part of the point- this is a philosophy class, not a marketing class. (Students might approach this more as a parody than a revision, in which case the final product could be quite entertaining.)

It's a good idea to require an accompanying written piece that explains the research behind the ad and argues for why it is ethically preferable to the original. The upside of a project like this is that the creative labor-especially if undertaken in a small group — can be an engaging and memorable experience for students, making their education seem less like a series of bureaucratic tasks. Displaying the results to the rest of the class is a great way to cap off the unit or the course. The downside is that the creative aspect of this project is time-consuming and could easily overshadow the analytical and research components. It also requires the ability to shoot and edit video; many students can do this on their smartphones and laptops, but for some it will present an unfair hurdle. Partly for these reasons, I have offered this assignment only as one option amongst several, and only for extra credit. Those who have taken on the assignment reported that they had no difficulty whatsoever with the technical aspectsshooting and editing the video was "easy", they told me, and it was obvious from the ads that students had fun in the process. The more difficult part was getting the students to engage in serious research about the drugs, beyond the sort of summary information already available to consumers in standard drug package inserts and websites like MedLine or rxlist.com. This suggests it is worth requiring students to cite peer-reviewed research, or to track down particular facts, such as the drug's "number needed to treat" (NNT) or information on its effectiveness compared to older drugs.

4. Conclusion: Benefits and Potential Pitfalls 
I have tried to show how one might approach teaching an ethical analysis of the United States' practice of DTC drug advertising in a philosophy course, and in particular in a bioethics course. The topic is extremely timely: we have seen increased scrutiny lately of the inner workings of the U.S. health care system, including the peculiar ways in which resources are priced and delivered, as the Affordable Care Act gradually takes effect. Just recently, in November 2013, we saw controversy erupt over revisions in the professional guidelines for the treatment of high cholesterol. These guidelines influence who gets prescribed statin drugs, which are taken by one quarter of Americans over age 40 and which - not coincidentally-are one of the most advertised classes of drugs (Kolata 2013). The controversy served as a reminder of just how inexact the science of public health can be, and just how vulnerable the whole enterprise is to the influence of marketing and financial conflicts of interest (Brody \& Light 2011). Meanwhile, other countries have been wrestling with whether to allow the type of DTC advertising permitted in the U.S. and New Zealand. So far the drug companies' efforts to introduce DTC ads in other countries have been unsuccessful - this practice that is so prevalent in our culture as to be almost invisible is still regarded by other countries as a threat to public health. In addition to being timely, drug advertising is universally "relevant" to students' lives, at least in the sense that they all have been exposed to it, if not directly targeted as its key demographic. In this respect students may relate more closely to this topic than many classic topics in bioethics, such as euthanasia or embryonic stem cell research. The availability of new and classic drug ads for use as in-class examples also caters to their appetite for multimedia approaches to teaching and their allegedly short attention spans.

Perhaps more important, this topic serves as a great way to expose students to the difficult work of ethically analyzing a question of public policy. Assessing this practice requires careful inquiry into conceptual, normative, and empirical controversies. It also requires examining the practice in its social, legal, and political context, rather than in the sanitized realm of philosophical thought experiments. It's messy. You and your class may not reach a completely satisfactory outcome, with all loose ends tied up neatly and a firm conviction that the practice is either perfectly fine or clearly problematic. But that's OK. As with the study of most moral controversies, sometimes it is enough simply to help students see how complicated the question is and what would be necessary to answer it.

One potential objection to including this topic is that it requires a more careful examination of the empirical literature than is possible or practical in a philosophy course. I have tried to suggest one workaround, which is to select and rely on review articles (like Mintzes 2012) that digest the vast literature and single out the most methodologically sound studies. This allows me to convey to students the importance of seeking empirical answers to empirical questions, while at the same time recognizing that not all studies can be taken at face value. Indeed this topic presents many opportunities to work on information literacy and scientific literacy at several levels-the clinical science during the drug approval process, the presentation of research results in the ads themselves, and the social science research that measures the health outcomes and economic impact of such advertising. Instructors may also use this as an opportunity for a more in-depth study of such topics as placebo-controlled randomized trials, experimenter bias, statistical significance, absolute vs relative risk, financial conflicts of interest, etc. An accessible discussion of some of these topics in the pharmaceutical context can be found in Goldacre (2012). Even a brief exposure to these scientific issues 
is worthwhile in light of the fact that Americans have, on average, very poor understanding of the most basic scientific concepts, including experimental design and probability (Miller 2004). Students who learn to critically evaluate the information in health-related advertising might actually be less susceptible to some of its harmful effects.

Another worry about studying DTC advertising is that-perhaps relative to other topics on your syllabus - students may find it boring or insignificant. A related worryindependent of student opinion-is that the topic is insignificant, not worthy of course time. Indeed, the topic is less gory than other bioethics topics and less wrapped up in immediate questions of life and death and raw human drama. Many advertised drugs are for relatively mundane medical conditions-seasonal allergies, toenail fungus, dry eyes, heartburn. Neither students nor bioethicists tend to be too interested in such things. However, from a public health standpoint, DTC advertising is wrapped up in a variety of issues that have serious implications for societal wellbeing-access to healthcare, cost of healthcare, medicalization of ordinary ailments, exploitation of vulnerable groups, etc. These issues may not be sexy, but they are quite important, and certainly of comparable importance to other public health issues commonly covered in bioethics courses, like vaccine mandates.

Finally, as with many topics in applied ethics, instructors will need to be careful to be respectful of students and their personal experiences, which may greatly inform the way they think about health-related issues. Drug ads can be quite fun to teach because they are so often absurd or unintentionally humorous. There is a danger, though, that poking fun at a particular ad can morph into making light of a given medical condition or the people who suffer from it. This may be especially problematic in cases of advertising for psychiatric medications. Instructors will hopefully have already established a classroom atmosphere in which students can engage in critical inquiry without offending each other, and it is important not to suspend this atmosphere when covering this topic. ${ }^{10}$

\section{AUTHOR BIO}

Vanessa Carbonell is Assistant Professor of Philosophy and Obed J. Wilson Professor of Ethics at the University of Cincinnati. She works mainly in ethical theory and moral psychology but has additional research and teaching interests in bioethics.

\section{WORKS CITED}

Angell, M. 2005. The truth about the drug companies. New York: Random House.

Beauchamp, T. and J. Childress. 2013. Principles of biomedical ethics, $7^{\text {th }}$ Edition. Oxford: Oxford University Press.

${ }^{10} \mathrm{I}$ am grateful to Amanda Roth, Dustin Tucker, and two anonymous referees for feedback on an earlier draft of this paper. Thanks also to Marie Jayasekera, Angela Potochnik, and Kyle Furlane for helpful discussion and assistance in tracking down references. Finally, I wish to thank the students in my Morality in Medicine classes at the University of Cincinnati in 2011, 2013, and 2014 for their enthusiasm and for tolerating my pedagogical experimentation. 
Brody, H. 2007. Hooked: ethics, the medical profession, and the pharmaceutical industry. Lanham, Maryland: Rowman \& Littlefield.

Brody, H., and D. Light. 2011. The inverse benefit law: How drug marketing undermines patient safety and public health. American Journal of Public Health 101 (3): 399-404.

Daniels, N. 1981. Health-care needs and distributive justice. Philosophy and Public Affairs 10: 146-179.

Donohue, J., M. Cevasco, and M. Rosenthal. 2007. A decade of direct-to-consumer advertising of prescription drugs. New England Journal of Medicine 357: 673-681.

Department of Health and Human Services (DHHS). 2010. Food and Drug Administration 21 CFR Part 202. Federal Register, 75 (59), 15376-87. Accessed July 17, 2013: < http://www.gpo.gov/fdsys/pkg/FR-2010-03-29/pdf/2010-6996.pdf>

Dworkin, R. 1972. "Paternalism." The Monist 56: 64-84.

FDA. 2012. Be smart about prescription drug advertising: a guide for consumers. Website. Accessed July 18, 2013: <http://www.fda.gov/Drugs/ResourcesForYou/Consumers/PrescriptionDrugAdv ertising/default.htm $>$

FDA Consumer Health Information. 2010. Keeping watch over direct-to-consumer ads. Accessed July 17, 2013: <http://www.fda.gov/downloads/ForConsumers/ConsumerUpdates/ucm107180. $\operatorname{pdf}>$

Gilbody, S., P. Wilson, and I. Watt. 2005. Benefits and harms of direct to consumer advertising: a systematic review. Qual. Saf. Health Care 14: 246-50.

Goldacre, B. 2012. Bad pharma: How drug companies mislead doctors and harm patients. New York: Faber and Faber.

Hall, S. 2001. The Claritin effect: prescription for profit. The New York Times Magarine March 11, 2001.

Hasman, A. and S. Holm. 2006. Direct-to-consumer advertising: should there be a free market in healthcare information? Cambridge Quarterly of Healthcare Ethics 15:42-49.

Heineman, M. and S. Froemke. (Directors) 2012. Escape Fire. Lionsgate.

Jayawardhana, J. 2013. Direct-to-consumer advertising and consumer welfare. International Journal of Industrial Organization 31: 164-180.

Kaphingst, K. and W. DeJong. 2004. The educational potential of direct-to-consumer prescription drug advertising. Health Affairs 23: 143-150. 
Kolata, G. 2013. Experts reshape treatment guide for cholesterol. New York Times, November 12, 2013. Accessed 12/12/13: http://www.nytimes.com/2013/11/13/health/new-guidelines-redefine-use-ofstatins.html

La Barbera, C. 2012. Irresponsible reminders: Ethical aspects of direct-to-consumer drug advertising. Ethics \& Medicine: An International Journal of Bioethics 28 (3): 95-112.

Lee D. and C.E. Begley. 2010. Racial and ethnic disparities in response to direct-toconsumer advertising. Am. J. Health Syst. 67:1185-90.

Liang, B., and T. Mackey. 2011. Reforming direct-to-consumer advertising. Nature Biotechnology 29: 397-400.

Miller, J. 2004. Public understanding of, and attitudes towards, scientific research: what we know and what we need to know. Public Understanding of Science 13: 273-294.

Mintzes, B. 2012. Advertising of prescription-only medicines to the public: Does evidence of benefit counterbalance harm? Annual Review of Public Health 33: 259-77.

Myers, D., M. Royne, and G. Deitz. 2011. Direct-to-consumer advertising: Exposure, behavior, and policy implications. Journal of Public Policy \& Marketing 30 (1): 110-118.

Mulligan, L. 2011. You can't say that on television: Constitutional analysis of a direct-toconsumer pharmaceutical advertising ban. American Journal of Law \& Medicine 37: 44467.

Nielson, K. 1989. Autonomy, equality, and a just healthcare system. International Journal of Applied Philosophy. 4: 39-44.

Nilson, L. 2010. Teaching at its best: a research-based resource for college instructors. San Fransisco, CA: Wiley.

Parks, J. and V. Wike. 2009. Bioethics in a changing world. New York: Prentice Hall.

Prince, M. 2004. Does active learning work? A review of the research. Journal of Engineering Education 93(3): 223-231.

Rabin, R.C. 2013. A glut of antidepressants. New York Times, August 12, 2013. Accessed 8/16/2013 http://well.blogs.nytimes.com/2013/08/12/a-glut-of-antidepressants/

Sandel, M. 2009. Justice: What's the Right Thing to Do? New York: Farrar, Strauss, and Giroux.

Schenker, Y., R.M. Arnold, and A. London. 2014. "The ethics of advertising for healthcare services." American Journal of Bioethics 14(3): 34-43. 
Umbach, P. and M. Wawrzynski. 2005. Faculty do matter: The role of college faculty in student learning and engagement. Research in Higher Education 46(2): 153-184.

Weimer, M. 2013. Learner-centered teaching: five key changes to practice. New York: Wiley.

Weisberg, R. (Director) 2012. Money and Medicine. Docurama.

Wellington, A. 2010. To ban or not to ban: Direct-to-consumer advertising and human rights analysis. Australasian Medical Journal 3: 749-66.

Womack, C. 2013. Ethical and epistemic issues in direct-to-consumer drug advertising: where is patient agency? Medicine, Health Care and Philosophy 16: 275-280. 